\title{
Smart Attendance System Applying QR Code
}

\author{
Md Rizal Md Hendry, Mohd Noah A. Rahman and Afzaal. H. Seyal
}

\begin{abstract}
The cardinal aim of this study to report an automated student attendance system modeled and developed for use at a Vocational school. This paper focuses on developing an application by using a QR code. This system enables us to speed up the process of taking attendance and would save us valuable teaching time. This is planned to help students avoid consequences that may result from poor attendances which will eventually penalized them from sitting their final examination as required by the administrators.
\end{abstract}

Keywords-QR code, Reed Solomon,error correction code, system design.

\section{INTRODUCTION}

Punctuality and regular attendance are the prerequisites that are commonly imposed in most schools. They are connected to emerging character behaviors such as initiative, respect, integrity and responsibility. Many established studies have shown that student attendance during lectures have positive correlations with their academic performances (Westerman et al., 2011; Dobkin et al., 2010; Chau and Kuo, 2012; Lin, 2011). Students determine commitment, initiative, respect and responsibility when they are in class and on time, at all times. The less class time students miss or absent, the more likely they will do well academically.

The traditional and normal way of taking attendance is by using pen and paper manually which is seemed as unproductive, repetitive and tedious processes. This mode of taking attendance will incur time lost instead of delivering lecture effectively especially if the population of a class is big.

As new technology rapidly evolves, there are various ways of capturing students' attendances. The widespread uses of smartphones at an unprecedented rate have revolutionized the way people access to information particularly in the education sector. There are various technologies available that enable and assist educators to streamline their attendance taking activities. A few available solutions are hardware incline such asusingradio frequency identification (Abdulkareem et al., 2014), biometrics (Shoewu et al., 2014; Dey et al., 2014; Alia et al., 2013), software based solutions for attendance management (Kumbhar et al, 2014; Al-Shammari, 2012) or both using software and hardware (Lokhande et al., 2013; Reda et al., 2011).

Mohd Noah A. Rahman is with the UniversitiTeknologi Brunei,Bandar Seri Begawan, BE 1410,Brunei Darussalam (phone: 673-246-1020; fax: 673246-1035; (e-mail: noah.rahman@ utb.edu.bn).

Afzaal H. Seyal is with the UniversitiTeknologi Brunei, Bandar Seri Begawan, BE 1410,Brunei Darussalam (phone: 673-246-1020; fax: 673-2461035; (e-mail: afzaal.seyal@uitb.edu.bn).

Md Rizal Md Hendrywas with the UniversitiTeknologi Brunei.
In this project, the proposed attendance system is developed by scanning the QR code using a webcam attached to a computer. Subsequently the data is recorded and deposited in a database for further retrieval and reporting purposes. The Reed Solomon error code correction is applied to determine the authenticity of the code scanned through the webcam. A report is produced and submitted to the administrator. If there exists a penalty in case attendance percentages fall below $85 \%$ set in the school's policy, a warning letter will be issued to the student.

The presentation of this paper is organized in the following sequences. A related background study is compiled and discussed. Next, a detailed system design and workflow is proposed. Subsequently a discussion on the findings is portrayed and finally a conclusion is drawn.

\section{RELATED BACKGROUND STUDY}

There exist various modes of attendance system applications being used in various situations such as in schools and higher institutions of learning. The most notable changes in most educational landscape today are the capitalization of technology in managing the attendance of students (GomisPorqueras et al., 2011).

A Learning Management Systems (LMS) proposed the use of real time face detection algorithms which automatically detects and registers student attending the class (Shehu and Dika, 2010).

A system which uses fingerprint verification technique was proposed by applying a technique known as extraction of minutiae which automates the process of attendance taking (Saraswat and Kumar, 2010).

A prototype system which uses facial recognition and detection technology combining with a neural network algorithm was developed to perform face detection and an eigenface method to perform facial recognition was implemented (Xiao and Yang, 2009).

Another study which confirmed the presence of a student attending a class was developed using a mobile phone via a Bluetooth connection. It will further query the existence of the student through the transfer of student's Media Access Control (MAC) address to the instructor's mobile phone (Jamil, 2011).

A few studies were conducted on the use of QR code for attendance systems (Deugo, 2015; Baban, 2014; Masalha and Hirzallah, 2014; Singh and Munukoti, 2013).

\section{RESEARCH APPROACH}

As presented in Fig. 1 below, this project focuses on developing a prototype to perform the basic function of 
inserting, retrieving and deleting information, scanning QR code, viewing and producing reports.

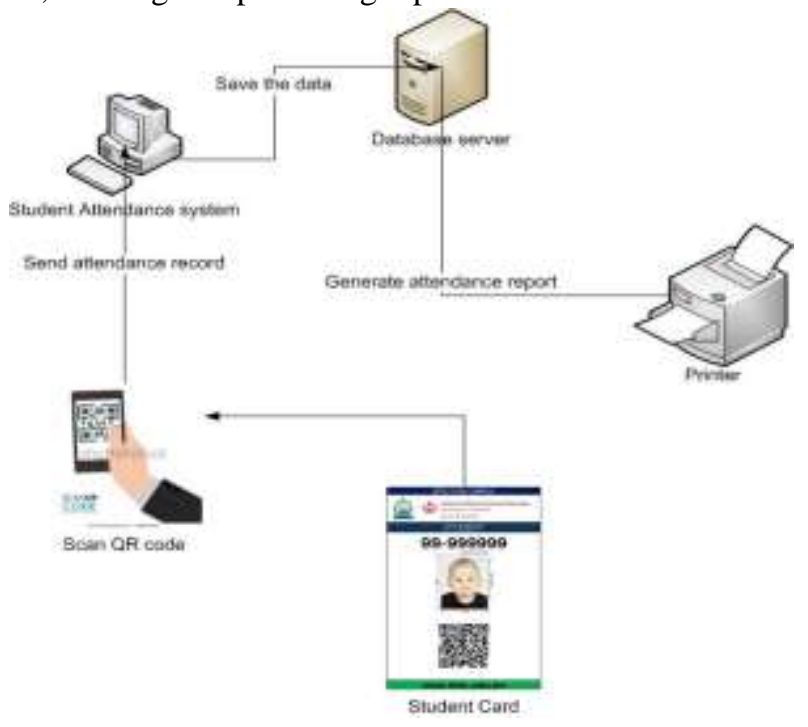

Fig. 1 Overall architecture of an attendance system

\section{A. Quick Response (QR) Code}

A $(\mathrm{QR})$ code is a two dimensional code used to record thousands of characters and numbers in a small image created by Denso-Wave Corporation of Japan in 1994. The QR code is arranged in columns and rows of black and white colours designed to be read by smartphone users (Shin et al., 2012). Users utilize the QR code can simply use the software decode built-in into the applications to convert scanned code images into the coded information and save it into the database (Ohbuchi et al., 2004).

\section{B. Reed Solomon Error Correction Code (ECC)}

Regardless of the design of the two-dimensional barcode, there will be errors. The image of the barcode may be damaged or unclear. In other words, the barcode obtained from scanning differs from the original. Therefore, it is essential to be able to detect and correct errors which may occur.

The error correction which is widely used is Reed-Solomon code. This is because it is easier to encode than other encoding techniques and the error correction code is small. Moreover, error detection and error correction can be performed quickly and efficiently.It allows correct reading even the bar code is damaged a lot. The reason is when the bar code scanner cannot recognize a bar code symbol, it will consider as an erasure.

Part of the strength of QR codes in the physical environment is their ability to withstand damage and remain to function even when a part of the QR code image is disguised, vandalized or indifferent.

This is accomplished by using the Reed-Solomon Error Correction Code algorithm where several serious algebra that occurs in the background when the QR code is created. The inventive data in the $\mathrm{QR}$ code is converted into a polynomial and number of unique points required to uniquely describe that polynomial is resolute, and the point set is added back into the
QR code therefore that it then also holds the original data expressed as a polynomial.

There are four error correction levels used for QR codes as depicted in Table 1.

TABLE I

QR CODE ERROR CORRECTION LEVEL

\begin{tabular}{|c|c|}
\hline Error Correction Level & Damage (\%) \\
\hline Level 1 & 7 \\
\hline Level 2 & 15 \\
\hline Level 3 & 25 \\
\hline Level 4 & 30 \\
\hline
\end{tabular}

\section{Masking}

This process is used to avoid features in the symbol where that can be might confuse a scanner, such as misrepresentative shapes that looks the locator patterns and large blank areas. Masking overturns certain modules of white becomes black and black becomes white, whereas parting others alone.

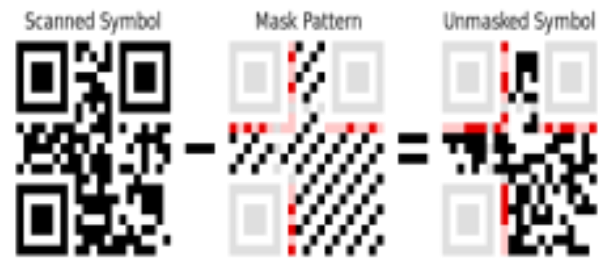

Fig. 2 Masking transformation

The masking transformation is easily applied or removes using the exclusive-or operation. The unmasking of the format information is shown below. Reading counter-clockwise around the upper-left locator pattern, we have the following sequence of bits. The white modules representa 0 and the black modules represent a 1 as a binary coded representation.

$$
\begin{array}{lc}
\text { Input } & 101101101001011 \\
\text { Mask } & \wedge 101010000010010 \\
\text { Output } & 000111101011001
\end{array}
$$

\section{SYSTEM DESIGN}

\section{A. System Flowchart}

The system flowchart as shown in Fig. 3 clearly demonstrates the process flow from the beginning of the application until the repository of data resided in the database. This software development technique and methodology still remains as one of the preferred technique used among software developers (Rahim et al, 1998 ${ }_{\mathrm{a}}$; Rahim et al,1998 )

Once registration is done, users then begin to login to the system. Thereafter, the scanning of $\mathrm{QR}$ code will proceed. After the scanning process is completed, the information is submitted by using the copy clipboard procedure and pasted on the insert form. Consequently, the data is stored in the database which has a profound benefit and ease of use (Rahman et al., 2004). This database is currently stored in a WAMP server. 


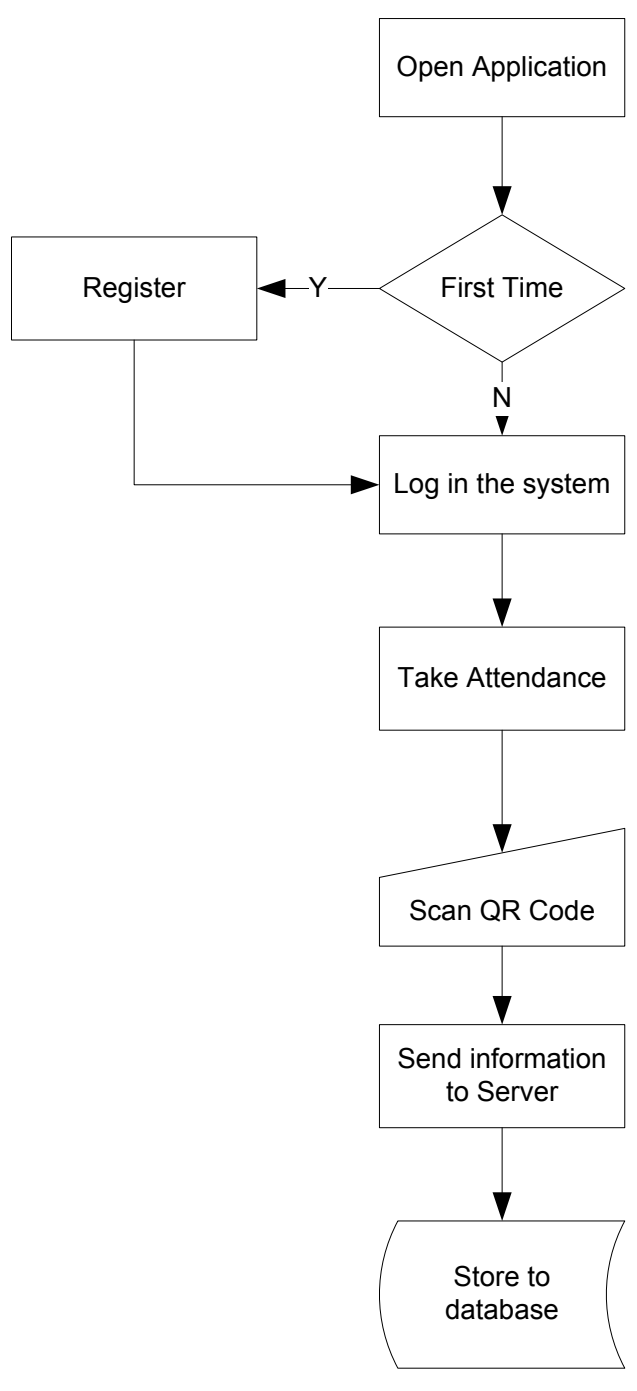

Fig. 3 Flowchart

\section{B. Entity Relationship Diagram (ERD)}

The ERDensures all the entities, relationships and the required attributes for the attendance system are available as depicted in Fig. 4. The ERD diagram has been widely used in most structured analysis and conceptual modeling because the approach is easy to understand, powerful to model real-world problems and it is readily translated into a database schema Song et al., 1995).

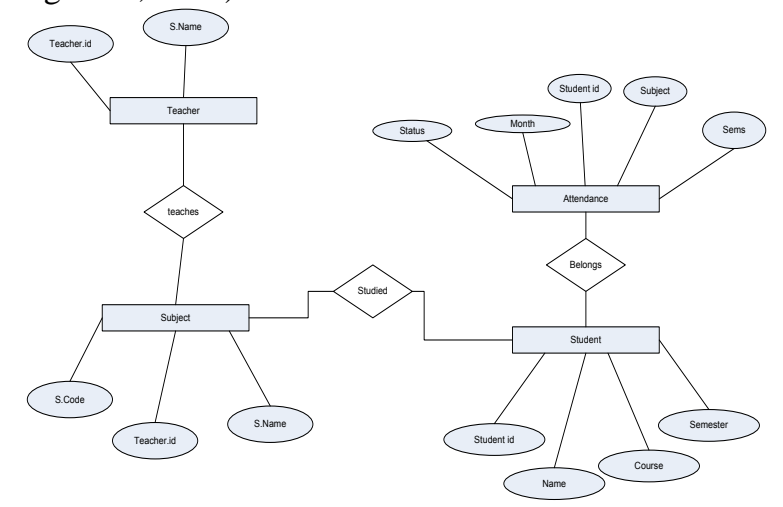

Fig. 4 Entity-Relationship Diagram

\section{SYSTEM IMPLEMENTATION}

This attendance system requires minimum hardware specification of Intel Pentium Dual core i5 with RAM size of $2 \mathrm{~GB}$ and minimum hard disk capacity of $500 \mathrm{~Gb}$.An additional device of an Android smartphone with camera equipment

The required software used for development process of the QR codes scan and Web based program requires an operating system Microsoft Windows 7 or Server with 64 bit. A web basedWAMP server (PHP, MySQL \& Apache) with an additional QR code scanner application.

The welcome page comes with five options as iconized in Fig. 5.

WELCOML admin, Locour

\section{SMART STUDENT ATTENDANCE SYSTEM}

SSAS

ISTE SVSE CAMPUS
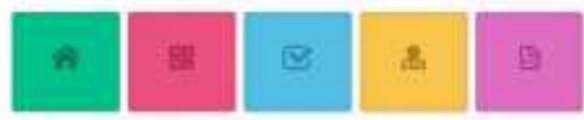

Fig.5 Welcome page

The scanning process of the QR codes is shown in Fig. 6.

WELCCNE admin, LOBOUT

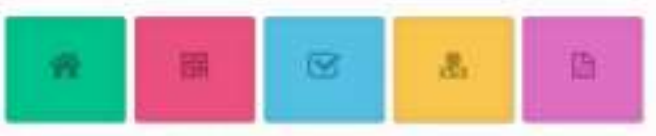

SCAN QR CODE HERE.
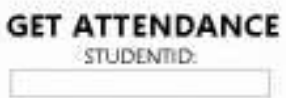

INSERT

Fig.6 Scanning process

The Reed Solomon ECC will detect errors and corrected them if available by producing the masking techniques as mentioned. This is shown in Fig. 7. 

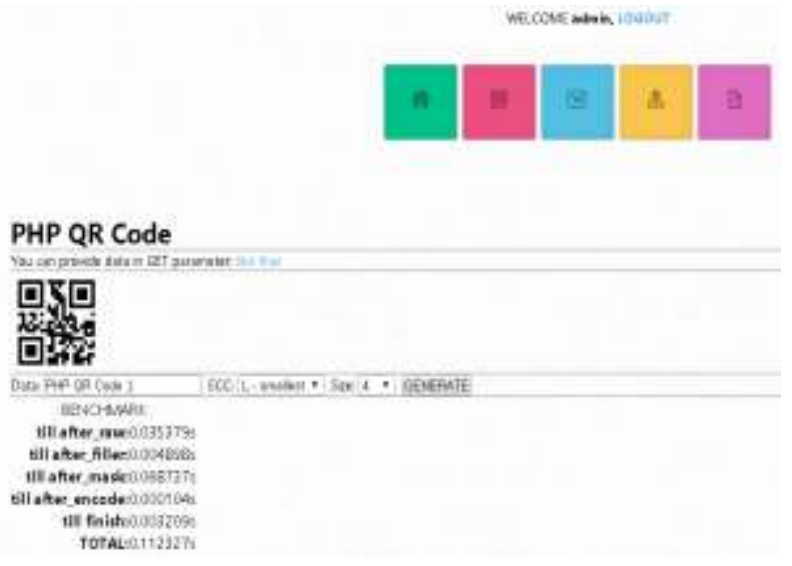

Fig. 7 Error correction process

The masking transformation is easily applied or removes using the exclusive-or operation. The unmasking of the format information is shown below. Reading counter-clockwise around the upper-left locator pattern, we have the following sequence of bits. White modules represent 0 and black modules represent 1 .

The checking of attendance is later reported to the relevant offices for attendance analysis as shown in Fig. 8.
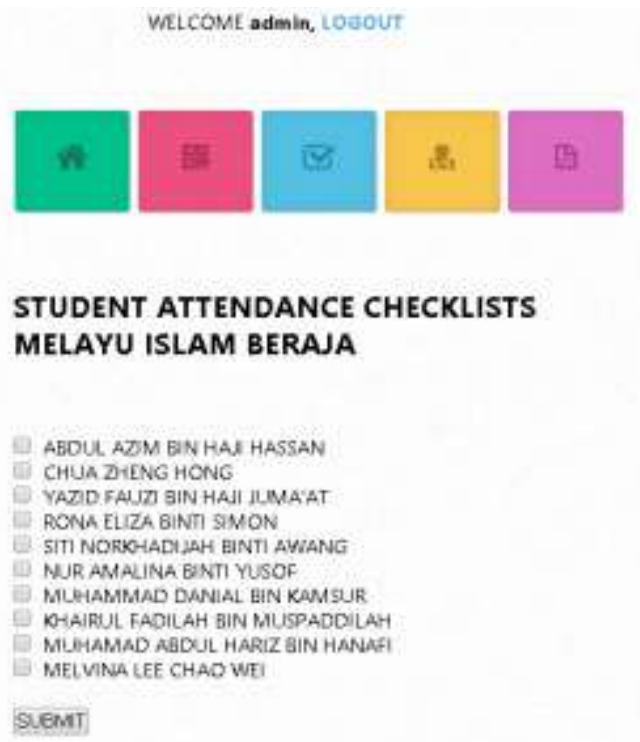

Fig.8 Attendance checklist reporting

\section{CONCLUSION}

This paper has presented an attendance system that utilizes the use of QR code. The proposed system stores all data repository in a database in a secure and protected database management systems (DBMS) namely the MySQL.

The core of the attendance system is to provide a reliable and functional attendance tracking and reporting system which enables administrator to identify and rectify those students who do not meet the minimum attendance as stipulated in the policy and academic regulations of the school. In addition, the attendance system will ultimately reduce administrative labor manually and minimized paper usage.

In future, we will provide an efficient algorithm to be developed as a networked version without the need to install the open source scanning application scanner.

\section{REFERENCES}

[1] J.W. Westerman, L.A. Perez-Batres, B.S. Coffey and R.W. Pouder, "The relationship between undergraduate attendance and performance revisited: Alignment of student and instructor goals,"Decision Sciences Journals of Innovative Education, vol. 9, no. 1, pp. 49-67, 2011.

[2] C. Dobkin, R. Gil and J. Marion, "Skipping class in college and exam performance: Evidence from a regression discontinuity classroom experiment," Economicsof Education Review, vol. 29, no. 4, pp. 566$575,2010$.

[3] P.T. Chau and Y. Kuo, "Examining factors relating to classroom attendance and performance," Journal of Studies in Education, vol. 2, no. 2, pp. 193-204, 2012.

[4] T. Lin, "Effects of current and prior skipped classes on current exam performance," Journal of Economic Educators, vol. 11, no. 2, pp. 12-24, 2011.

[5] V. Shehu and A. Dika, "Using real time computer vision algorithms in automatic attendance management systems, " in Proc. $32^{\text {nd }}$ International Conference on Information Technology Interfaces (ITI), 2010, pp. 397402.

[6] C. Saraswat and A. Kumar, "An efficient automatic attendance system using fingerprint verification technique," International Journal on Computer Science \& Engineering, vol. 2, no. 2, pp. 264-269, 2010.

[7] Q. Xiao and X.D. Yang, "A facial presence monitoring system for information security," IEEE Workshop on Computational Intelligence in Biometrics: Theory, Algorithms, and Applications, 2009, pp. 69-76

[8] T. Jamil, "Automatic attendance recording system using mobile phone," Telecommunication Forum (TELFOR), 2011, pp. 1297-1299.

[9] P. Gomis-Porqueras, J. Meinecke and J.A. Rodrigues-Neto, "New technologies in higher education: Lower attendance and worse learning outcomes?," Journal of Policy Analysis and Reform, vol. 18, no. 1, pp. 69-83, 2011.

[10] D.H. Shin J. Jung and B.H. Chang, "The psychology behind QR codes: User experience perspective," Computers in Human Behaviour, vol. 28, 2012, pp. 1417-1426.

[11] E. Ohbuchi, H. Hanaizumi and L.A. Hock, "Barcode readers using camera device in mobile phones," in Proc. International Conference on Cyberworlds, 2004, pp. 260-265.

[12] ${ }_{\mathrm{a}}$ M.M. Rahim, M.N. Rahman and A.H. Seyal, "Use of software development techniques: Experiences of Brunei Darussalam," Malaysian Journal of Computer Science, vol. 11, no. 1, 1998, pp. 9-21.

[13] „M.M. Rahim, A.H. Seyal and M.N. Rahman, "Use of software development methods: An empirical study in Brunei Darussalam," Information and Software Technology, vol.39, no.14-15, 1998, pp. 949963.

[14] M.N. Rahman, A.H. Seyal and A.Y. Mohamed, "An empirical framework of DBMS usage in Brunei Darussalam," in Proc. Of the $5^{\text {th }}$ Annual Global Information Technology Management World Conference (GITM), June 2004, pp. 189-192.

[15] I.Y. Song, M. Evans and E.K. Park, "A Comparative Analysis of EntityRelationship Diagrams," Journal of Computer and Software Engineering, vol. 3, no. 4, 1995, pp.427-459.

[16] A. Abdulkareem, D.U. Ike and F. Olowononi, "Development of a radio frequency identification based attendance management application with a pictorial database framework," International Journal of Research in Information Technology, vol. 2, no. 4, 2014, pp. 621-628.

[17] O. Shoewu, N.T. Makanjoula and S.O. Olatinwo, "Biometric-based attendance system: LASU Epe campus as case study," American Journal of Computing Research Repository, vol. 2, no. 1, 2014, pp. 8-14.

[18] S. Dey, S. Barman, R.K. Bhukya, R.K. Das, B.C. Haris, S.R.M. Prasanna and R. Sinha, "Speech biometric based attendance system," in Proc. Twentieth National Conference on Communications (NCC), 2014, pp. 1-6.

[19] M.A. Alia, A.A. Tamimi and O.N.A. Al-Allaf, "Integrated system for monitoring and recognizing students during class session," The 
International Journal of Multimedia \& Its Applications (IJMA), vol. 5, no. 6, 2013, pp. 45-52.

[20] A.A. Kumbhar, K.S Wanjara, D.H. Trivedi, A.U. Khairatkar and D. sharma, "Automated attendance monitoring system using the android platform," International Journal of Current Engineering \& Technology, vol. 4, no. 2, 2014, pp. 1096-1099.

[21] Z. Al-Shammari, " Benefits of using tested attendance system to enhance student attendance and achievement in higher education," Journal of Advanced Social Research, vol. 2, no. 3, 2012, pp. 120-125.

[22] P. Lokhande, D. Kotkar and P. Nikam, "Combined RFID-Biometric based MIS for student information, " International Journal of Engineering Trends and Technology, vol. 4, no. 3, 2013, pp. 307-310.

[23] A. Reda, S. Panjwani and E. Cutrell, " Hyke: Alow cost remote attendance tracking system for developing regions," in Proc. The $5^{\text {th }}$ ACM Workshop on Networked Systems For Developing Regions, 2011, pp. $15-20$.

[24] D. Deugo, "Using QR-codes for attendance tracking," in Proc. $11^{\text {th }}$ International Conference on Frontiers in Education: Computer Science and Computer Engineering (FECS 2015), 2015, pp. 267-273.

[25] F. Masalha and N. Hirzallah, "A student attendance system using QR code," International Journal of Advanced Computer Science and Application, vol. 5, no. 3, 2014, pp. 75-79.

[26] M.H.M. Baban, "Attendance checking system using Quick Code for students at the University of Sulaimaniyah," Journal of Mathematics and Computer Science, vol. 10, 2014, pp. 189-198.

[27] D.N. Singh and C.K. Munukoti, "Attendance monitoring system using ARM9 with QR code,", International Journal of Latest Trends in Engineering and Technology (IJLTET), vol. 2, no. 1, January 2013, pp. 246-250. 